\title{
THE JUSTIFICATION OF THE DENIAL OF THE DIVORCE THESIS
}

\author{
Prof. PhD. Sudhakar VENUKAPALLI, \\ The English and Foreign Languages University Hyderabad, \\ INDIA, \\ Email: sudhakarvenu.efluniversity@gmail.com
}

\begin{abstract}
The contemporary philosophical understanding of scientific rationality fundamentally distinguishes itself from the conservative positions by what may be considered a categorial reorientation by which it is meant that it replaces the old categories by the new ones in terms of which the essential nature of the structure and dynamics of science are described and explained. In the beginning, the radicalization of the categorial framework has been brought through category transformation, which is very well exemplified in the nullification of the discovery-justification distinction. Apart from this parasitic semantic content, 'discovery' carried a negative meaning in terms of what it is not. With the nullification of the distinction, the semantic content of discovery has become not only autonomous, and positive but also, comprehensive so much as to become the focal concept in grasping the essence of scientific activity. These changes have fundamentally altered the discourse about discovery in ways that can be of momentous significance to science education (Schickore and Steinle, 2006). An attempt is made in this paper to illuminate how the denial of the divorce thesis has been justified by the philosophical arguments of Marcello Pera(1981, 1994), Robert McLaughlin (1982), John Worrall (1985,2003)and Jarrett Leplin(1987,1997,2009) and Thomas Nickels(1985,2003,2014).
\end{abstract}

Keywords: scientific discovery; scientific practice; context of justification; epistemic significance; divorce thesis;

\section{INTRODUCTION}

The traditional discourses of the problem of scientific discovery normally taken to be the methods of discovery such as, the method of analysis and synthesis, inductive method, deductive method, retroductive method, analogical reasoning, model building, etc. However, valuable such discussions might be, they have started giving diminishing returns. First of all, many of those methods, going by their conscious adoption by practicing scientists are of a limited generality. Secondly, to the extent some of those methods have a great generality as in the case of analogical reasoning and model-building, the discussions of those methods per $s e$ is, epistemologically speaking, less important than the implications they have for our construal of the overall nature of scientific knowledge. Though such a discussion might clarify and explicate the nature of these methods utilize in scientific practice, they will not directly place scientific practice within a radically new perspective that is transparent to the students and practitioners of science who very much need to understand those dimensions of scientific practice which are either overlooked or soft pedaled by the conventional picture of science. Hence it would be beneficial to study the different dimensions of the contemporary 
philosophical positions on discovery in terms of its various constituents such as the nullification of discovery-justification distinction that is overlooked by the conventional understanding of science.

\section{REACTIONS TO LARRY LAUDAN'S CHALLENGE}

The contention that discovery and justification are logically distinct from each other has been a major plank of the attack on the possibility of a philosophical account of discovery. Larry Laudan, who maintains the impossibility of a logic of discovery and who maintains a strict distinction between discovery and justification, challenged the prodiscovery philosophers to show that the methods of generation per se do carry special epistemic weight, that is, to establish that the methods of generation as such have special epistemic force. The pro-discovery philosophers like Pera and McLaughlin attempt to meet Laudan's challenge by trying to establish what Nickles calls the per se thesis. It may be noted that the per se thesis has to be established in a non-trivial way. As Peter Achinstein (1970) and others have shown, virtually any argument used in the context of discovery could, in principle, be found in the context of justification and vice versa. Hence care must be taken in establishing the identity-relation while justifying the per se thesis. Similarly, care must also be taken to see that the identity thesis must not result in making the philosophical account of discovery as a shadow of that of justification. More importantly, the relation between them must be one of de jure and not de facto (Nickles, 1985). After all a de facto_relation amounts to merely saying that what happened in a generative context, in fact carries probative weight. On the other hand, a de jure relation amounts to saying that it did so by virtue of its role in generation. To establish the per se thesis one must show that at least some moves made in the context of discovery have de jure relevance to justification of the claim under consideration. As Laudan holds, de facto relevance is not enough to establish a philosophically significant connection between discovery and justification. In fact, Laudan might even grant such a de facto relevance. By granting only a de facto relevance Laudan and others uphold what we might call difference thesis about discovery and justification relation.

In countering Laudan's challenge, Pera, McLaughlin and others try to establish an identity relation between discovery and justification. Finding the Identity thesis of Pera, McLaughlin and others highly wanting and even as attempts at an unrealizable goal, Nickles comes out with what may be called an Identity-In-Difference thesis about discoveryjustification relation. The question is whether such a thesis seeks to establish per se thesis. Nickles says that it might not. But nothing is lost since establishing per se thesis is neither necessary nor possible for nullifying the distinction between discovery and justification, at least to the extent that this distinction stands in the way of winning for discovery a philosophical legitimacy. In what follows, I try to explicate the attempts of Pera, McLaughlin and others to nullify the distinction between discovery and justification.

\section{PERA AND MCLAUGHLIN'S ATTACK ON DIVORCE THESIS}

In his article 'Inductive Method and Scientific Discovery', Pera attacks what he calls discontinuist thesis of hypothetico deductivists and puts forward what he calls the continuist thesis, according to which, "a hypotheses springs from the very same argument which provides the initial reasons for its plausibility" (Pera,1981,p.158). According to Pera the Hypothetico-deductive Model suffers from a logical paralysis accruing from the fact that the initial probability being zero, no amount of positive results would increase the probability of a hypothesis and this is counter-intuitive. The second logical paralysis accrues from the fact 
that in the hypothetico-deductivist model there is no limit to test just as there is no limit on the quantity of observations the crude inductivist has to collect. Pera points out that if the inductivist is compelled to observe everything, the Hypothetico-deductivist is forced to test everything. But this would block al scientific activity (Pera, 1981,p.159) The only way out, according to Pera, is to acknowledge that the plausibility considerations are not postinvention additions to an hypothesis but are constitutive of its conception and advancement such that "A hypothesis is not an a-logical or pre-logical guess but the plausible conclusion of an inference and hence the result of an induction" (Pera, 1981,p.157).

Undoubtedly Pera confronts Laudan's challenge head on by attempting to show that justification cannot even make a start and if at all it does start, can never reach its end, unless we concede the logicality of the invention of the hypothesis and thus break the distinction between discovery and justification. The question is, how far Pera is successful in this endeavor.

Nickles says that Pera has not established per se thesis, for he has made discovery derivative from justification. This is because he has not established that the probative force of the arguments is due to the fact that they play a generative role. Secondly, since it is possible to test a hypothesis by persons other than the one who generated the hypothesis, it is difficult to maintain that the plausibility of the judgment made by the inventor has a logical bearing on the justification. In fact Pera admits it when he attempts to explain such plausibility in terms of the fact that generation was guided by constraints. But this implies that the second parties can assess the prospects of a hypothesis independently of the source. It may or may not be the case that such an ignorance of the source adversely affects the efficiency of scientific procedure. But that question has nothing to do with the issue whether the relation between discovery and justification is one of logical necessity, which Pera has failed to establish. However, it may be noted that Pera has made, wittingly or unwittingly, an important point. The de jure relation that he seeks to establish as a logical entity can be watered down into a pragmatic necessity. That is to say, what Pera considers to be a logical feature should be treated instead as a practical guide in making a choice among a host of competing candidates for the position of a tentative hypothesis. This need arises in connection with the demands of economic viability, practical convenience and work-efficiency. It may be objected that Pera's point by doing so, looses epistemological significance. However, the topic of economy of research very much forms a part of the discussion of rationality and methodology, more and more so as the equations between logic and methodology, and logic and rationality are being weakened, Secondly, it may be objected that the practical interpretation of what Pera takes to be a logical point brings down the relation between discovery and justification from the de jure level to de facto level and thus Pera is left to compromise his per se thesis. But as Nickles says, the economically required de facto linkage of generation to justification undercuts the Popperian claim that no information used to construct a theory ever counts at all in its support (Nickles, 1985) In short, though Pera fails to establish a de jure relation between discovery and justification, the attempt is not futile. For Pera establishes a relation which is however weak as a de facto relation is sufficient to undercut the Popperian construal of the distinction in terms of psychological versus logical.

McLaughlin makes a distinction between context of generation, context of preliminary evaluation and context of final assessment - a distinction which looks like that of Laudan. However, the final evaluation, according to McLaughlin, depends upon the preliminary evaluation not only in the sense that the prior assessment precedes empirical test 
and thus must establish plausibility of an hypothesis but also in fixing non-zero initial probability very much required by the Bayesian construal of probability assessment. Similarly, according to McLaughlin, what happens in the context of generation is crucial to the preliminary assessment. The considerations that go along with the generation of a hypothesis might engender 'advancement' arguments for a new hypothesis $\mathrm{H}$ in the context of generation and the same argument may serve the purpose of 'enhancement' for $\mathrm{H}$ and thereby fix the prior-probability whose function is the posterior probability that accrues in the context of final evaluation. McLaughlin (1982) says that "the aim of a logic of invention (i.e., a philosophical account of discovery as generation) is to explicate the 'advancement of plausible hypothesis". However, McLaughlin fails to establish a de jure coupling, because he has not shown that the considerations, which bring about 'enhancement' of hypothesis in the context of preliminary appraisal, do so because of the fact that they have brought about an advancement of that hypothesis in the context of generation. Secondly, in a full-blooded logical relation between these contexts, the common considerations should not have diminishing utility. But though we may not accept Popper's strong statement that no information used to construct a theory ever counts at all in its support, we cannot overlook the fact that McLaughlin has not advanced any argument against the possibility of the progressive diminishing of the utility of those considerations. That is to say, it remains an open question whether the considerations may be very strong for the purpose of advancement and less strong for the purpose of enhancement and positively weak for the purpose of final evaluation. After all, the identity of the considerations does not guarantee non-variance of the epistemic power.

\section{EPISTEMIC SIGNIFICANCE OF DISCOVERY: JOHN WORRALL AND JARRETT LEPLIN}

John Worrall seeks to counter Laudan's challenge by showing that the divorce thesis is wrong since " in order to decide whether a particular empirical result supports or confirms or corroborates a particular theory the way in which that theory was developed or constructed needs to be known - more especially, it has to be checked whether or not that empirical result was itself involved in the construction of the theory" (Worrall,1985 ,p.301). Those who reject any link between discovery and justification, think of justification always in terms of novel predictions. But this is wrong because it is historically true that many a times novelty has not been insisted upon. That is to say, many times confirmation of a theory was accepted as genuine when it was based upon a fact known before the theory came into existence. But it is also true that many a time 'confirmations' based upon facts known prior to the theory were rejected as spurious. Worrall draws our attention to this peculiar historical fact of the diametrically opposite points of view towards confirmation in terms of already known facts. This curious historical phenomenon has generated diametrically opposite points of view in confirmation theory with J S Mill and others treating the temporal priority of the facts as being irrelevant to the confirmatory role and Whewell and his followers insisting upon novelty as a precondition for a genuine confirmation. Perhaps, both of them were right and perhaps they were speaking at cross-purposes.

Worrall by resolving the conflict tries to arrive at a via-media point of view according to which a fact, which is known prior to theory i.e., which is not novel, can be used for confirmation of the theory if it has not played a role in the construction of the theory. This heuristic view of empirical support concurs with the non-temporal view, which does novelty a necessary condition for confirmatory role. It agrees with the temporal view to the extent it 
stipulates and supports on historical ground the thesis that if knowledge of a fact is used in the construction of a theory it is illegitimate to use that fact in confirmation the theory. That is to say, "even if a theory entails an accepted empirical result, the theory is not supported by that result, if the result was used in the construction of the theory" (Worrall, 1985,p.301) It may be pointed out that it is not always easy to detect whether or not a piece of our knowledge of prior facts has been utilized both in the construction and in the confirmation of the theory. But this is precisely what makes discovery a methodologically important domain and related it to the context of justification. That is to say, in order that out justification be not trivial and therefore spurious, it is necessary to take into account that part of the story of a theory which is prior to justification, namely, the construction of a theory.

Worrall's heuristic view insists that the role of our knowledge of facts prior to the emergence of a theory is epistemologically important. Though those facts do not contribute to confirmation they have an important role in the success of a theory. After all, even Whewell agreed that his exclusive emphasis on novel predictions presupposes a belief that the theory cannot have made the correct predictions by chance. But this assumption cannot be conclusively proved. The rationality of our belief is somewhat adversely affected by this missing link. To a great extent the heuristic role of factual knowledge acquired prior to theory in the construction of the theory compensates for this. Of course, known facts (prior to theory) do also confirm. In this way Worrall attempts to establish the truth of the per se thesis and the falsity of the divorce thesis. But unfortunately, the terms of the per se thesis in Worrall's scheme are negative. It only tells us in what way the context of discovery should be kept at a distance from that of justification on order that justification be genuine. It does not at all tell us anything about the positive role discovery factors play in the process of justification. In fact it makes a virtue of what the divorce theories treat as a vice. Though Worrall's thesis, like that of McLaughlin and Pera, undercuts the divorce thesis, it fails to establish the per se thesis. However, it is to Worrall's credit that he brings out the epistemological significance of the discovery context in spite of its lack of positive bearing on justification.

Hence, Worrall can be credited with a double achievement, namely, weakening the divorce thesis and, more importantly, strengthening the independent epistemological significance of the discovery process. However, Worrall seems to think that the question of whether or not something has gone into the construction of a theory is not a trouble-shooter for there are very clear-cut cases, which make the answer transparent. But the question is whether such clear-cut cases are standard one. It may be that in standard cases the material of construction may not be articulated except from hindsight. Secondly, the so-called knowledge of the old facts when utilized in the constriction of theory may undergo a metamorphosis by the very fact of its role in construction such that our knowledge of old facts does not remain old. This is especially so in the case of explanatory theories. The acquired novelty of such old knowledge might contribute not only to the plausibility of the hypothesis but even to the acceptance of it, whenever "acceptance" is considered in terms other than the veracity of the test-implications.

Jarrett Leplin attempts to present an alternative version of same thesis. Worrall's negative per se thesis was left to apply to the construction and evaluation of any type of theories. Leplin confines the applicability of his thesis to the domain of only one type of theories, namely, theories of realist import i.e., theories which invoke reference to the unobservable deep-structures that are resorted to in explaining the observable phenomena. Leplin's strategy is to show that if the per se thesis, at least in its negative form is not 
accepted, then the autonomy of explanatory theories with realist import gets adversely affected and such an autonomy is axiomatic for any convincing philosophy of science.

Leplin accepts the widely shared view that not all positive instances of a theory's laws are confirmatory, although it is unclear and controversial what more the confirmation requires. He finds that the difficulty accrues from an ambiguity in the notion of confirmation. Different types of theories might require different types of confirmation. The degree of stringency of confirmation, according to Leplin, is directly proportional to the explanatory depth of the theories. The theories with realist import are the deepest, didactically speaking of all the theories and hence require most stringent conformation. One way of characterizing the stringency in this connection is by accepting that a favorable epistemic evaluation must be in terms of an empirical result that is independent of, or different in kind from, results that have a formative role in the generation of the theory confirmed. That is to say "inference to the truth or reference of a theory is warranted, if at all, only by confirmations independent of results that instantiate empirical laws that function as premises in rational reconstructions of the reasoning that generates the theory. For the epistemic realist, at least, justification depends on discovery” (Leplin, 1987 ,p.809). Of course Leplin's thesis is contingent upon the existence of the type of theories which realism looks upon as paradigmatic. In other words, Leplin must presume that non-realism is a false thesis . Leplin accepts this and holds against non-realism what he considers to be their failure to help us understand the ability of a theory to predict successfully phenomena that instantiate no law having any formative role in the reasoning, which produced the theory.

The significance of Leplin's attempt lies in the fact that it goes a long way in establishing some sort of a de jure relation between discovery and justification. But this is done at the cost of the breadth of the magnitude, which per se thesis had in the previous attempt. That is to say, in Leplin's scheme the per se thesis stands, if at all, within the domain of theories of realist import. Undoubtedly, it is a credit to Leplin that he brings to bear discovery-justification relation on the distinction between deep structural theories and phenomenological theories. However, the critics of Leplin might point to a possible circularity here; the stringency of confirmation is sought to be articulated in terms of realist non-realist distinction and unless the latter distinction is established in terms of independent and logical terms, Leplin's position becomes circular. In other words, Leplin has to establish the realist position on the basis of something other than stringency of confirmation. Leplin (2009) says,

"Having taken a position on this question, arguing that justification extends to theoretical hypotheses, I came to wonder about the nature of justification generally. This is not a belated discovery of the skeptical problem or a reconsideration of what I took to be unproblematic. It is simply an interest in the possibility of locating epistemic advance in science within a broader understanding of the nature of epistemic justification. Now that I know that justification extends to theory, I am taking a step back and asking what justification is."

Further, it may be noted that the stringency of confirmation in terms of novel facts on the one hand, and such theories having a real import in the realist sense of 'real' on the other are not logically continuous with each other in the sense that one does not logically imply the other, however compelling psychologically their association be. This fact very much erodes the logical strength of the relation between discovery and justification that is construed in very strong colours by Leplin. 


\section{GENERATIVE JUSTIFICATION/DISCOVERABILITY: THOMAS NICKELS}

Establishing the per se thesis on de jure lines is impossible. But, according to Nickles, it is not necessary also, because discovery has been established as methodologically important in its own right apart from any connection to justification. Because discovery has an autonomous methodological significance, it is not necessary to establish per se thesis. However showing an identity-in-difference relation between discovery and justification even on de facto lines is a significant advance beyond the classical view of Positivists and Popperians. By showing that justification itself is shot through discovery tasks of search and generation one is able to arrive at a unitary picture. Such a relation if recognized, however loose, at least highlights the role of heuristics in scientific thinking in general and context of justification in particular, not only economically but also epistemically. In other words, the through-going dualism between discovery and justification shared by both enemies of discovery like Popper and friends of discovery like Hanson was undoubtedly put on the defensive by people like McLaughlin and Pera, who though they could not establish a monism of discovery and justification, nevertheless, considerably reduced the gap between them. The gap is further reduced by acknowledging, as do the followers of Lakatos like Urbach (1978) and Wimsatt(1980) that the evaluative weight of a theory increases if it is found promising in terms of future discoveries. Nickles (1985) in his paper "Beyond Divorce: Current Status of the Discovery Debate" seeks to further reduce the gap and establish an almost, if not literal, de jure relation by invoking the notion of discoverability. It may be noted that whereas Urbach and Wimsatt extend the notion of discovery forward, Nickles does it backwards. Taking both of them together the context of discovery of a theory extends over past, present and future.

Is discovery epistemically relevant to justification in the sense of providing surplus support for the generated claims? In answering 'yes to this question, Nickles invokes the notion of "justification as potential discovery" or "generative 'justification" or "discoverability". By this he means the rationally reconstructed discovery path that maps a derivation of the new claims from data. That is to say, the type of thinking that starts from data and ends up in a theory as different from the type of thinking, which goes from theory to observational test implications. Anyone who does not commit himself totally to hypotheticodeductive model can recognize the type of justification that is associated with the former mode of thinking where "justifying a claim establishes its 'discoverability' in the sense that, regardless of how the claim was discovered or invented historically - regardless of how or why it was first thought of - it could have been discovered in the rationally specified manner had the necessary information and analytical techniques been available"( Nickles, $1985 \mathrm{p}$. 195) Of course, it is true that the "discoverability" as explicated above and the actual process of discovery are very rarely, if at all, identical. But "Despite this divorce of initial conception from discoverability, discovery-type moves will be central to the latter, and certainly important in searching for discoverability arguments. Scientists search for theoretical derivational justifications even of well-confirmed hypotheses. Such searches are at once searches for derivations and searches for rational discovery paths" (Nickles,1985.p.195196). It is obvious that Nickles' notion of empirical support is different from that of the hypothetico-deductivist model which allows only a consequentialist construal of justification. According to Nickles, both consequential justification and generative justification are important and in fact, equal importance is attached to both in mature sciences. 
Nickles admits that he has established a de jure relation between discoverability and generative-justification but not between discovery and justification. But to the extent generative-justification provides surplus justification, which is over and above that, provided by a consequential justification, the divorce thesis has been given a jolt. Nickles (2014) says,

"Scientific practices do not neatly separate out in this manner, either logically or temporally. Search-and-discover operations are ubiquitous in research, from problem formulation to predictive testing. For example, writing and evaluating research proposals requires heuristic appraisal - evaluation of the future promise of fertility of problems, approaches, models, techniques, pieces of apparatus, etc. Although normative, this exercise often involves constructing what might be called "discovery sketches" - plausible lines of development and application - and it differs from epistemic appraisal of truth based on the past empirical track record. We also meet discovery issues at the meta-level".

In establishing, in however round about and loose a way, the positive bearing of discovery on justification, Nickles has driven home the point that the divorce thesis is based upon the dogma of consequentialism. If one realizes that justification in actual scientific practice is construed in a sense broader than the one construed by consequentialism, the divorce thesis gets sufficiently weakened not to stand in the way of the legitimation of discovery as a worthy object of philosophical study.

\section{CONCLUSION}

It may be pointed out that the semantic content of "discovery" had been till now earmarked or specified in terms of its antagonistic relation with justification. This divorcespecified content is bound to give way to divorce-free content once the divorce thesis is rejected. With this the category of 'discovery' undergoes a transformation. It is this categorytransformation in connection with "discovery" that constitutes the first major achievement of the contemporary view. It thus showed that the dominant notion of discovery was parasitic upon a myopic understanding of 'justification'. The conception of discovery resulting from such a transformation becomes synonymous with the whole process of scientific inquiry and a philosophical study of discovery becomes, instead of an appendage to a supposed logic of justification, a study of the whole development of an idea from its inception to its acceptance. Gutting brings out this point very vividly when he says: "the positivists' exclusive emphasis on the testing of already developed hypotheses did not just overlook one aspect of science; it misrepresented the entire enterprise. The case for discovery is no longer a call to add a new topic to our discussions of scientific methodology but to transform them by regarding discovery as the primary goal of all science."(Gutting,1980,p.222). Nickles' contention is that 'discovery' has a philosophical importance independent of whatever it has due to its methodological proximity with justification. That is to say one must not loose sight of the philosophical i.e., methodological importance of discovery in itself, even if one has sufficient arguments against the divorce position.

As we have seen, the relation between discovery and justification is one of identity-indifference. It is both strong and weak. It is strong enough for countering divorce thesis and yet loose enough to permit independent relevance of discovery for methodological inquiry into science. The independent philosophical significance consists in its ability to shed light upon those aspects of scientific thinking, which were eclipsed by the justificationist dogma with its divorce thesis. The dogma refused to attach any methodological significance to what preceded justification in the consequentialist sense. Once we free ourselves from such an idea we may be able to recognize certain things in the context of discovery that might have 
consequences for the fundamental epistemological problem, namely, the nature and, limits of scientific knowledge. One can find such a promise in the nature of scientific problems and the constraints that characterize their solutions. The contributions of the contemporary philosophers of science are a major advance in the discourse of scientific discovery.

\section{BIBLIOGRAPHY:}

[1] Achinstein, Peter. "Inference to Scientific Laws" in R. Steuwer (ed.), Minnesota Studies in the Philosophy of Science, Vol.5, (1970), Minneapolis: University of Minnesota Press.

[2] Gutting, Gray. "The Logic of Invention", in T. Nickles (ed.), Scientific Discovery, Logic and Rationality. (1980) Dordrecht, Holland: D. Reidel, p 222.

[3] Leplin, Jarett. 1987. "The Bearing of Discovery on Justification". Canadian Journal of Philosophy Vol. 17, N.4, (1987), p. 809.

[4] Leplin, Jarrett . A Novel Defense of Scientific Realism. New York: Oxford University Press. 1997

[5] Leplin, Jarrett . A Theory of Epistemic Justification, Chapel Hill NC: Springer, 2009.

[6] McLaughlin, R.: "Invention and Appraisal", in McLaughlin (ed.), What? Where? When? Why?, (1982), p.79 Dordrecht, Holland: D. Reidel.

[7] Nickles, Thomas. "Beyond Divorce: Current Status of the Discovery Debate". Philosophy of Science. Vol.52, (1985), pp. 117-206.

[8] Nickles, T. "Evolutionary Models of Innovation and the Meno Problem," in L. Shavinina (ed.) International Handbook on Innovation. Amsterdam: Elsevier Scientific Publications, (2003),pp. 54-78. [iê]

[9] Nickles, Thomas . "Scientific Discovery" in Martin Curd and Stathis (ed.) The Routledge Companion to Philosophy of Science . (2014), London: Routledge

[10] Pera, M. "Inductive Method and Scientific Discovery", in M.D. Grmek, R.S. Cohen, and G. Climino (eds.), On Scientific Discovery. (1981), p.158. Dordrecht, Holland: D. Reidel.

[11] Pera,M. The Discourses of Science. Chicago: Chicago University Press, 1994

[12] Schickore, J. and Steinle, F. (ed). Revisiting Discovery and Justification: Historical and Philosophical Perspectives on the Context Distinction, Dordrecht: Springer. 2006.

[13] Urbach, P. "The Objective Promise of a Research Programme", in Radnitzky and Andersson (ed). Progress and Rationality in Science. (1978), pp. 99-113.

[14] Wimsatt, William C. 'Reductionistic Research Strategies and their Biases in the Units of Selection Controversy' T. Nickles (ed.), Scientific Discovery: Case Studies, Dordrecht, Holland: D. Reidel,1980.

[15] Worrall, J. 1985. "Scientific Discovery and Theory - Confirmation" in J.Pitt (ed.). Change and Progress in Modern Science. Dordrecht, Holland: D. Reidel,(1985),p. 301.

[16] Worrall, J. "Normal Science and Dogmatism, Paradigms and Progress: Kuhn versus Popper and Lakatos" in T. Nickles (ed.): Thomas Kuhn. Cambridge: Cambridge University Press, 2003. 